\title{
Masses Staining Positive for DNA-Isolated from the Stratosphere at a Height of $41 \mathrm{~km}$
}

\author{
Wainwright $\mathbf{M}^{1,2,3 *}$, Wickramasinghe $\mathrm{NC}^{2,3}$, Harris $\mathrm{M}^{4}$ and Omairi $\mathrm{T}^{1}$ \\ ${ }^{1}$ Department of Molecular Biology and Biotechnology, University of Sheffield, Sheffield S10 2TN, UK \\ ${ }^{2}$ Buckingham Centre for Astrobiology, University of Buckingham, Buckingham MK18 1EG, UK \\ ${ }^{3}$ Institute for the Study of Panspermia and Astroeconomics, Gifu, Japan \\ ${ }^{4}$ Formerly Cardiff University, UK
}

\begin{abstract}
Clumps of stratospheric material with individual diameters of 10-30 micrometers were isolated in a sterile manner from a height of $41 \mathrm{~km}$. The masses showed no obvious morphology, but stained positive for DNA and are therefore considered to be unequivocally biological. We suggest that the masses are arriving to the stratosphere from space and not upcoming from Earth; evidence is provided to support this view.
\end{abstract}

Keywords: Membrane staining; Stratosphere sampling; Earth biology

\section{Introduction}

During the early years of this century, researchers at the University of Cardiff, working in collaboration with Indian workers, isolated from the stratosphere (at a height of $41 \mathrm{~km}$ ) a particle mass which exceeded 10 micron in size and which stained positive for living matter (using a fluorescent carbocyanine stain) [1]; the particles were assumed to be bacteria. The senior author and co-workers, used Live/Dead stain to confirm the presence of such masses, and showed that they contain live and dead particles [2]. They also isolated, on growth media, bacteria and fungi from these stratosphere samples $[2,3]$ and provided further evidence for the presence of bacteria in the stratosphere $[2,4,5]$. Confirmation of the presence of cultureable bacteria was then provided by a number of other workers [6-8].

Some of the data from the above mentioned research was not evaluated at the time. Since recent studies have demonstrated the presence of unusual biological entities in the stratosphere [9-11] it appears an opportune moment to reassess some of this neglected data. The aim of the present paper is therefore to discuss some of this earlier data in relation to these new findings relating to the presence, and origin, of the biological entities currently being isolated from the stratosphere.

\section{Materials and Methods}

\section{Stratosphere sampling}

The stratospheric air samples were obtained from a height of 40-41 $\mathrm{km}$ using a cryosampler attached to a balloon. Strenuous efforts were made to avoid contamination from the balloon and of the sampling probe during the balloon's ascent into space, further details of which are reported elsewhere. The balloon carrying a cryosampler payload was launched on 21 January, 2001 from Hyderabad, India. The cryogenic sampler comprised a 16-probe assembly. Each probe had a volume of $0.35 \mathrm{l}$ and was made of high vacuum grade stainless steel. It was capable of holding a vacuum at $10-6 \mathrm{mb}$ and a pressure of $600 \mathrm{~b}$. The temperature cycling ability of the probes was tested between $-246^{\circ} \mathrm{C}$ and $140^{\circ} \mathrm{C}$. To minimise contamination, only the minimum required electron-beam welds were made and the interior was electroplated. The probes and manifolds were cleaned with acetone and four washes of demineralised water; the complete assembly was steam baked and finally heated with infrared lamps to $140^{\circ} \mathrm{C}$. To prevent collection of out gassed substances from the gondola, a $2 \mathrm{~m}$ intake tube (sterilised as above) formed a part of the payload assembly and the assembly was tethered to the balloon by a sterilised $100 \mathrm{~m}$ line. The probe mouth was covered during balloon assent and had a metallic (Nupro) valve, which could be remotely operated, from the ground.

\section{Membrane staining}

The micropore filters on which material from the stratosphere was deposited were aseptically cut in a Class 2 cabinet. Samples were then transferred onto new glass microscope slides which had been washed, and polished and then placed in a sterile petri dish. DAPI (10 $\mu \mathrm{l}, 0.1 \mathrm{mg} / \mathrm{ml}$ in SDW) was added to each sample. The stain was left to develop under low light for $15 \mathrm{~min}$. A cover slip was then placed on the filter piece and the sample was observed using an epifluorecence microscope; images were captured using sigma scan software. Controls using known bacteria were also included in order to confirm that the staining process worked. In the case of For DIOC $_{6}$ staining, $1 \mu$ of a stock solution of $0.1 \mathrm{mg}$ per $\mathrm{ml}$ in ethanol diluted with sdw to give a 1:100 solution.

\section{Results and Discussion}

Figures 1 and 2 show masses isolated from the stratosphere at a height of $41 \mathrm{~km}$ and associated images following staining with the DNA-specific stain DAPI. Both masses appear to be amorphous and do not possess evidence of cell walls or appendages which would aid their identification as individual organisms. DAPI staining shows that all of the masses contain uniformly-distributed DNA; as a result, we conclude that they are biological. Figure 2 shows the top part breaking down into particles. Another amorphous mass, isolated from $41 \mathrm{~km}$, is shown in Figure 3; positive staining with $\mathrm{DiOC}_{6}$ shows this mass is also biological ( $\mathrm{DiOC}_{6}$ is a fluorescent stain used to stain endoplasmic reticulum, vesicles, membranes and mitochondria). It is noticeable that the masses are not made up of individual components of the size of

*Corresponding author: Wainwright M. Department of Molecular Biology and Biotechnology, University of Sheffield, Sheffield S10 2TN, UK, Tel: 4401142224410; E-mail: m.wainwright@sheffield.ac.uk

Received March 12, 2015; Accepted March 14, 2015; Published March 18, 2015

Citation: Wainwright M, Wickramasinghe NC, Harris M, Omairi T (2015) Masses Staining Positive for DNA-Isolated from the Stratosphere at a Height of $41 \mathrm{~km}$. Astrobiol Outreach 3: 130. doi:10.4172/2332-2519.1000130

Copyright: (c) 2015 Wainwright M, et al. This is an open-access article distributed under the terms of the Creative Commons Attribution License, which permits unrestricted use, distribution, and reproduction in any medium, provided the original author and source are credited. 


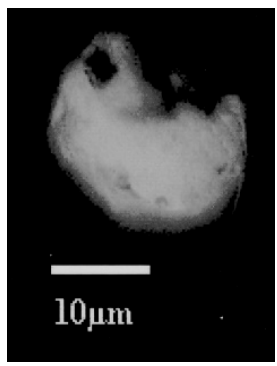

A
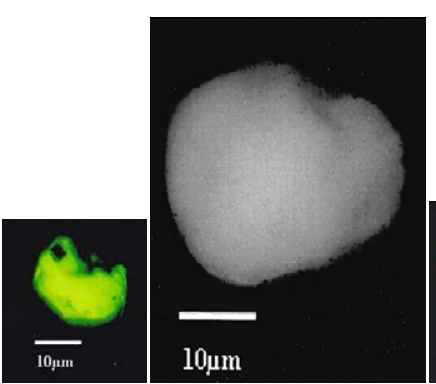

B

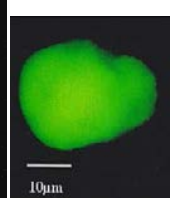

Figure 1: Particle masses isolated from the stratosphere, stained with DAPI.
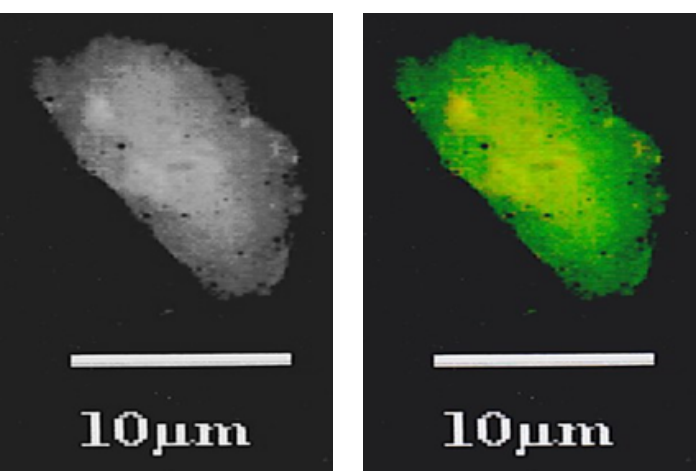

Figure 2: Particle mass isolated from the stratosphere, stained with DAPI, showing edges breaking into nanoparticles.
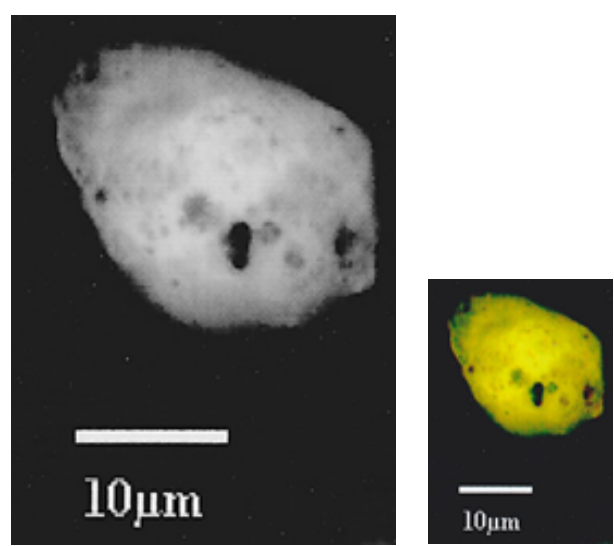

Figure 3: Particle mass isolated from the stratosphere, stained with $\mathrm{DiOC}_{6}$.

bacteria (around 1 micron) instead, the irregular, particulate edge of the masses (Figure 2) suggests that they are made up of nanoparticles, such as nanobacteria or even viruses. Unfortunately, the degree of magnification used and the resultant resolution does not allow us to provide any further information on this point. All of the biological masses shown exceed 10 microns in size, the largest, shown in Figure $1 \mathrm{~B}$ exceeding 30 microns. These dimensions are significant because it is generally accepted that particles bigger than 5 microns cannot cross from the Earth through the tropopause and into the stratosphere $[12,13]$, let alone be elevated to a height of $41 \mathrm{~km}$. It is possible however, that larger particles could be elevated into the lower stratosphere, by a very large volcanic eruption. The sampling trip was however, made 2 years after the previous last volcanic eruption, so any particles from this source would have deposited back to Earth before they could be sampled by the cryosampler. It is highly significant that no pollen, grass, algae or fungal spores (some of which are similar in size to the observed masses) was seen on the membranes on which was deposited material from $41 \mathrm{~km}$. It is impossible to believe that there exists a mechanism which could transfer the fluorescent-staining masses from Earth to 41 $\mathrm{km}$ without also delivering examples of such Earth biology.

An alternative explanation is that the masses are made up of biological particles which are small enough to be carried in to the stratosphere at a height of $41 \mathrm{~km}$ or above, where they were reaggregated and compressed into the masses seen in Figures 1 and 2 . Such masses comprised of terrestrial biological material might then be posited to have been sampled by the cryosampler on the journey back to Earth. Because of the exceedingly low ambient densities prevailing in the stratosphere the operation of such a particle-compression mechanism appears to be exceedingly unlikely. It is possible, however, that a much larger cometary bolide, containing both nanometre and micrometre-sized biological entities (viruses and bacteria), disintegrated in the upper stratosphere and recondensed into the amorphous DNA imbued structures shown in Figures 1-3. This could well be similar to the reconstitution of calcite and carbon dust from the material of an exploding meteorite described by Corte et al. [14].

In the case of the samples discussed in the present paper care was taken at every stage of their collection and processing to avoid contamination. We also checked some possible, common contaminants, such as dandruff, skin and laboratory dust and none were similar in appearance to the masses shown in the above figures.

On the balance of probabilities, we conclude therefore that the masses were sampled as they were incoming to Earth from space. Recent studies have shown that naked DNA can survive re-entry from space into the atmosphere of Earth $[15,16]$. It is probable however that, instead of travelling to Earth in a naked unprotected state, the incoming masses found here were shielded from UV and other extremes, by cosmic dust or by being embedded in small ice particles.

\section{Acknowledgement}

The contributions of P. Rajaratnam and D.Loyd are gratefully acknowledged.

\section{References}

1. Harris MJ, Wickramasinghe NC, Lloyd D, Narlikar JV, Rajaratnam $P$, et al (2002). Detection of living cells in stratospheric samples. Proceedings of SPIE Conference 4495: 192-198.

2. Wainwright $M$, Wickramasinghe NC, Narlikar JV, Rajaratnam P, Perkins (2004) Confirmation of the presence of viable but non-cultureable bacteria in the stratosphere. International Journal of Astrobiology 3: 13-15.

3. Wainwright M, Wickramasinghe NC, Narlikar JV, Rajaratnam P (2003) Microorganisms cultured from stratospheric air samples obtained at $41 \mathrm{~km}$. FEMS Microbiology Letters 218: 161-165.

4. Wainwright M, Wickramsinghe NC, Narlikar JV, Rajaratnam P (2004) Are these stratospheric nanoparticles bacteria? Microbiology 150: 756-758.

5. Wainwright M, Weber P, Smith J, Hutcheon I, Klyce B, et al. (2004) Studies on bacteria-like particles sampled from the stratosphere. Aerobiologia 20: 237240

6. Shivaji S, Chaturvedi P, Begum Z, Pindi PK, Manorama R, et al. (2009) Janibacter hoylei sp. nov., Bacillus isronensis sp. nov. and Bacillus aryabhattai sp. nov., isolated from cryotubes used for collecting air from the upper atmosphere. International. Journal of Systematic Evolutionary Microbiology 59: 2977-2986.

7. Yang Y, Itahashi S, Yokobori S, Yamagishi A (2008) UV-resistant bacteria isolated from upper troposphere and lower stratosphere. Biological Science in Space 22: 18-25. 
Citation: Wainwright M, Wickramasinghe NC, Harris M, Omairi T (2015) Masses Staining Positive for DNA-Isolated from the Stratosphere at a Height of $41 \mathrm{~km}$. Astrobiol Outreach 3: 130. doi:10.4172/2332-2519.1000130

Page 3 of 3

8. Yang Y, Yokobori S, Yamagishi A (2009) Assessing panspermia hypothesis by microorganisms collected from the high altitude atmosphere. Biological Space in Science 23: 151-163.

9. Wainwright $\mathrm{M}(2008)$ The high cold biosphere. In Focus-Proceedings of the Royal Microscopical Society 12: 33-41.

10. Wainwright M, Rose CE, Baker AJ, Bristow KJ, Wickramasinghe NC (2013) Isolation of a diatom frustule fragment from the lower stratosphere $(22-27 \mathrm{~km})$ Evidence for a cosmic origin. Journal of Cosmology 22: 1083-10188.

11. Wainwright M, Rose CE, Baker AJ, Bristow KJ, Wickramasinghe NC (2013) Isolation of biological entities from the stratosphere $(22-27 \mathrm{~km})$. Journal of Cosmology 22: 10189-10196.

12. Kasten F (1968) Falling speed of aerosol particles. Journal of Applied Meteorology 7: 944-947.
13. Rosen JM (1969) Stratospheric dust and its relationship to the meteoric influx Space Science Review 9: 58-89.

14. Corte VD, Reitmeijer FJM, Palumbo ARP (2013) Meteoric $\mathrm{CaO}$ and carbon smoke particles collected in the upper stratosphere from an unanticipated source. Tellus B 65 .

15. Thiel CS, Tauber S, Schutte A, Schmitz B, Nuesse H, et al. (2014) Functional activity of plasmid DNA after entry into the atmosphere of Earth investigated by a new biomarker stability assay for ballistic spaceflight experiments. Plos One 9(11): e112979.doi:10.1371/journal.pone.0112979.

16. Wainwright M, Alharbi S, Wickramasinghe NC (2006) How do microorganisms reach the stratosphere? International Journal of Astrobiology 5: 13-16. 